\title{
Controversial data on simvastatin in asthma: What about the rat model?
}

\author{
This article was published in the following Dove Press journal: \\ Journal of Asthma and Allergy \\ 14 July 2010 \\ Number of times this article has been viewed
}

\author{
Thomas Tschernig' \\ Wolfgang Bäumer ${ }^{2}$ \\ Reinhard Pabst' \\ 'Institute of Functional and Applied \\ Anatomy, Hannover Medical School, \\ Hannover, ${ }^{2}$ Institute of Pharmacology, \\ Toxicology and Pharmacy, University \\ of Veterinary Medicine, Hannover, \\ Germany
}

\begin{abstract}
The effects of simvastatin on lung inflammation in asthma are controversial. Reduction of inflammation and hyperreactivity has been reported in studies using murine models of asthma. In contrast, a clinical study has not found beneficial effects in patients. The rat model of asthma has some distinct advantages and is still widely used in industrial studies. Therefore, the role of simvastatin was investigated in this rat model using intraperitoneal and intratracheal administration. With both simvastatin administration routes, the relative and absolute numbers of neutrophils, eosinophils, and lymphocytes were only partially reduced after increasing dosages (0.1, 1.0, and $10 \mathrm{mg}$ per animal). The most obvious effect was on CD4 T cell numbers, which were reduced in most treatment groups. The results presented here suggest that treatment with simvastatin differs between species, and that it is too early for extrapolation of these data to humans.
\end{abstract}

Keywords: simvastatin, inflammation, rat, asthma

\section{Introduction}

Simvastatin has been shown to be a promising new drug for the treatment of allergic asthma. The first relevant report was published by McKay et al in $2004 .^{1}$ In that report, 4.0 or $40 \mathrm{mg} / \mathrm{kg}$ body weight of the drug was administered to mice either orally or intraperitoneally (IP), leading to a reduction in inflammatory cell infiltrates and eosinophilia in bronchoalveolar lavage (BAL) fluid. Furthermore, ovalbumin (OVA)-induced interleukin (IL)-4 and IL-5 levels in BAL fluid were found to be reduced after treatment. However, the exact mechanism by which statins mediate anti-inflammatory and immunomodulatory actions is not well understood. By inhibiting 3-hydroxy-3-methylglutaryl coenzyme A reductase, the mevalonate synthetic pathway is affected, which results in inhibition of prenylation of proteins. Prenylated proteins play a crucial role in the regulation of cell growth and signal transduction. Additionally, by inhibition of cholesterol synthesis, statins are lipid raft modulators. Lipid rafts act as platforms, bringing together molecules essential for activation of immune cells (eg, the "immunologic synapse"). By these and other described effects, statins exert immunomodulatory actions in vitro and in vivo. ${ }^{2}$ In $2007 \mathrm{Kim}$ et al analyzed the mechanisms of action of simvastatin in a murine model of asthma. ${ }^{3}$ This group showed regulation of $\mathrm{G}$ proteins, mitogen-activated protein kinases, and NF-kappaB. A very recent report from Zeki et al found that the mevalonate pathway was partially involved in the action of simvastatin during allergic airway inflammation. ${ }^{4}$ In contrast, a clinical study has not found therapeutic anti-inflammatory effects in asthma.
Correspondence:Thomas Tschernig Institute of Anatomy and Cell Biology, Saarland University Medical Faculty, 6642I Homburg/Saar, Homberg, Germany $\mathrm{Tel}+49684$ II62 6143

Email thomas.tschernig@uks.eu 
It is always difficult to compare animal and human studies for many reasons, eg, models, dosage, and duration of treatment, as well as read-out parameters. However, the rat as a model for asthma is widely used in industrial studies and offers some specific advantages, as have been summarized previously. ${ }^{6}$ The main aspect is that the rat, similar to humans, has a mucosal blood supply from the bronchial arteries. In contrast, mice do not have a bronchial circulation. Data from a Fisher rat model of asthma are presented here after treatment with simvastatin $10 \mathrm{mg}$ IP or 0.1 and $1.0 \mathrm{mg}$ simvastatin IP or intratracheally (IT). The IT application was investigated because a local or topical treatment, eg, a TLR2/6 agonist, would be very attractive for clinical application and has been effective in rat model testing. ${ }^{7}$

\section{Materials and methods}

\section{Animals}

Female Fisher rats (8-10 weeks of age [Charles River, Sulzfeld] and kept in the central animal laboratory facility [Medical School of Hannover]). Several experiments were performed with animals in numbers from 3-9 per group. Food and water were provided ad libitum. Rats were maintained in a separated minimal-barrier sustained facility and were microbiologically monitored according to the recommendations of the Federation of Laboratory Animal Science Associations. All procedures were approved by the Lower Saxony district government in Hannover, Germany.

\section{Asthma induction}

On days 0 and 7, all rats were sensitized with $1 \mathrm{mg}$ OVA (Sigma, Deisenhofen) and $200 \mathrm{mg}$ of $\mathrm{Al}(\mathrm{OH})_{3}$ (Sigma) in $1 \mathrm{~mL} 0.9 \%$ (sterile, pyrogen-free) $\mathrm{NaCl}$ (Braun, Melsungen) applied subcutaneously. A second adjuvant, concentrated preparation of $5 \times 10^{9}$ heat-killed Bordetella pertussis bacilli (donated by the manufacturers, Chiron Behring, Marburg) in $0.4 \mathrm{~mL} 0.9 \% \mathrm{NaCl}$ was given IP at the same time. On day 13 , the animals were challenged with $250 \mu \mathrm{L} 0.5 \%$ OVA IT. Under short ether (Baker, Deventer) anesthesia, they were suspended in a hanging position by a rubber band fixed to the teeth of the upper jaw. The solution was instilled after intubation of the trachea via the oral cavity. The correct position of the tube was checked by blowing air into the lung before application.

\section{Treatment}

The animals were treated with $1.0 \mathrm{mg}$ or $0.1 \mathrm{mg}$ simvastatin IT or with $10 \mathrm{mg}, 1.0 \mathrm{mg}$, and $0.1 \mathrm{mg}$ IP one hour before the challenge. The high dose of simvastatin $10 \mathrm{mg}$ (approximately
$40 \mathrm{mg} / \mathrm{kg}$ ) could not be applied via the IT route. Vehicle application served as the treatment control. Simvastatin was supplied by Merck, UK. The animals were sacrificed 25 hours after challenge. Three animals were included in each experiment with the following exceptions: statin treatment $1 \mathrm{mg}$ IP (two experiments each, $\mathrm{n}=6$ ) and statin treatment $1 \mathrm{mg}$ IT (one experiment, $\mathrm{n}=1$, and one experiment, $\mathrm{n}=9$ ).

\section{Animal dissection and preparation of bronchoalveolar and interstitial cells}

The animals were sacrificed on day 15 under deep ether anesthesia, during which the abdominal wall was opened and the animals killed by aortic exsanguination. The trachea was dissected and a cannula was inserted in situ. The lungs were lavaged with $5 \times 5 \mathrm{~mL}$ cold $\left(4^{\circ} \mathrm{C}\right) 0.9 \% \mathrm{NaCl}$. The fluid was recovered by gentle aspiration. The lavage fluid was pooled, and on average over $90 \%$ of the volume was retrieved from all animals. The pooled BAL fluid was centrifuged $(400 \times \mathrm{g}$, 10 minutes) washed, centrifuged again, and the resulting cell pellet resuspended in $1 \mathrm{~mL}$ phosphate-buffered saline (PBS, containing $1 \%$ bovine serum albumin and $0.1 \%$ sodium azide). A mechanical method was used for lung cell extraction. To this end, the whole left lung was passed through a metal sieve with two rounded tweezers. The sieve was rinsed with $40 \mathrm{~mL}$ PBS and the suspension was centrifuged, washed, and resuspended as described above. The right lung was filled with PBS-diluted embedding medium (1:4) and deep frozen. Cryostat sections were performed and stained with hematoxilyn and eosin.

\section{Differential cell counts}

Total cell numbers in BAL fluid and the lung interstitium (complete left lung) were determined in a Neubauer counting chamber using standard staining with Tuerk's solution (Merck, Darmstadt). Eosinophils, neutrophils, and monocytes/macrophages were assessed on slides prepared by centrifuging $1 \times 10^{5}$ cells in anticoagulant $(8.8 \mathrm{~g} \mathrm{NaCl}$, Merck, $+0.99 \mathrm{~g}$ ethylenediaminetetraacetic acid $+50 \mathrm{~g}$ bovine serum albumin, in $1 \mathrm{~L}$ distilled water) for five minutes at $200 \times \mathrm{g}$. The slides were fixed in acetone for 10 minutes. Cells were morphologically identified after Quik-Diff (DQ, Dade Behring) staining. At least 300 cells were differentiated on each slide.

For flow cytometry, cells were transferred onto microtiter plates $\left(1 \times 10^{6}\right.$ per well). The staining was performed as described previously. ${ }^{7}$ In brief, after the cells were washed twice with PBS (containing 1\% bovine serum albumin and $0.1 \%$ sodium azide) the first antibody was incubated for 20 minutes at $4^{\circ} \mathrm{C}$. The procedure was repeated with the secondary antibody. 
The cells were analyzed using a FACScan flow cytometer (Becton Dickinson, Mountain View, CA) focusing on the lymphocyte cluster. $\mathrm{CD}^{+} \mathrm{T}$ cells were identified as $\mathrm{T}$ cell receptor positive/CD8 negative cells. Dendritic cells were identified as CD103/major histocompatibility complex Class II positive cells. All antibodies were monoclonal mouse anti-rat (Serotec, Oxford). Unconjugated antibodies were detected with phycoerythrin (PE)-conjugated secondary antibody (kappa PE, Dianova, Hamburg) and biotinylated primary antibodies with Red 670-streptavidin (Gibco, Gaithersburg, MD). Isotypematched antibodies served as the control.

\section{Statistical analyses}

The experiments were performed on different days. Data from different experiments for one group have not been pooled to show the day-to-day variation of the model and treatment. Means and significant differences were calculated using GraphPad Prism 4.00 (Graph Pad Prism Software, San Diego, CA). The Mann-Whitney test was used to compare experimental groups. Values of $P<0.05$ were taken as statistically significant.

\section{Results}

\section{Tissue inflammation}

After the OVA challenge in the sensitized Fisher rats, strong peribronchial and perivascular leukocyte cuffs were observed in controls as well as in treated animals. Eosinophils were abundant in lung tissue in the control groups, and also after IP and IT simvastatin.

\section{Leukocyte accumulation in bronchioalveolar lavage fluid and lung tissue}

Cellular analysis of BAL fluid and lung tissue revealed asthma-like inflammation, as indicated by a strong leukocyte accumulation in BAL fluid, as well as in lung tissue of OVAchallenged rats (Figure 1). The number of total cells in BAL fluid was reduced after treatment with simvastatin $10 \mathrm{mg}$ IP, but no significant differences were detected in the numbers of total cells between the control group and the treatment group after treatment with simvastatin 0.1 or $1 \mathrm{mg}$ IP or IT (Figure 1A). No differences were seen in lung tissue (Figure 1B). Eosinophil numbers were reduced after one experiment using simvastatin $10 \mathrm{mg}$ IP and after another using simvastatin $0.1 \mathrm{mg}$ IT. In other experiments, simvastatin treatment had no effect on numbers of eosinophils in BAL fluid (Figure 2A). Neutrophils in BAL fluid were reduced again only after treatment with simvastatin
$10 \mathrm{mg}$ IP (Figure 2B). The number of $\mathrm{CD}^{+}{ }^{+} \mathrm{T}$ cells was reduced in most of the experiments or at least showed a tendency towards lower numbers after the different routes and dosages of simvastatin (Figure 3A). In contrast, no effect was seen on the numbers of dendritic cells (Figure 3B).

\section{Discussion}

In this study, the effect of different dosages and application routes of simvastatin was investigated in allergic airway inflammation in Fisher rats. There are several reports demonstrating anti-inflammatory and immunomodulatory actions of statins in different in vitro and in vivo models. ${ }^{2,8,9}$ One potential mechanism by which statins mediate antiinflammatory and immunomodulatory actions is the inhibition of 3-hydroxy-3-methylglutaryl coenzyme A reductase in the mevalonate synthetic pathway which results in impaired prenylation of proteins. Prenylated proteins have pleiotropic effects in the regulation of cell growth and signal transduction. Statins also act as modulators of lipid rafts which are membrane microdomains playing a substantial role in immune cell interaction. ${ }^{2}$ It has to be noted that statins may differ in their anti-inflammatory efficacy. It was demonstrated that lovastatin and fluvastatin inhibit granulocytemacrophage colony-stimulating factor-stimulated human eosinophil adhesion to intercellular adhesion molecule-1. Interestingly, simvastatin, mevastatin, and pravastatin failed to show inhibitory actions in this in vitro assay. ${ }^{9}$

We wanted to test the efficacy of simvastatin in a rat model of asthma because, in contrast with mice, rats have a bronchial circulation, and in this respect rat physiology is closer to that of humans than that of the mouse. ${ }^{6}$ The data on leukocyte subsets in BAL fluid or left lung tissue are presented as absolute numbers to avoid misleading conclusions when relative numbers (percentages) are given. A robust effect of simvastatin has been shown in murine asthma models. ${ }^{1,3,4}$ Simvastatin was associated with a reduction in inflammatory cells and cytokine numbers in those reports. Similar results were obtained for lovastatin, another statin. However, although inhibition of eosinophil influx could be confirmed in a more recent study, no effects on typical chemokines (eg, eotaxin, TARC, $\mathrm{LTB}_{4}$, and the Th2 cytokines, IL-4 and Il-13, were found. ${ }^{8}$ Simvastatin also failed as a therapeutic drug in a clinical study. The same lack of efficacy was also shown for atorvastatin. Even the effect of atorvastatin as add-on therapy to inhaled glucocorticoids was only moderate..$^{10}$ In the present study, a limited therapeutic effect was shown in the Fisher rat asthma model. A high dose of simvastatin $10 \mathrm{mg}$ per rat, which is approximately $40 \mathrm{mg} / \mathrm{kg}$ body weight, was injected IP and 
A

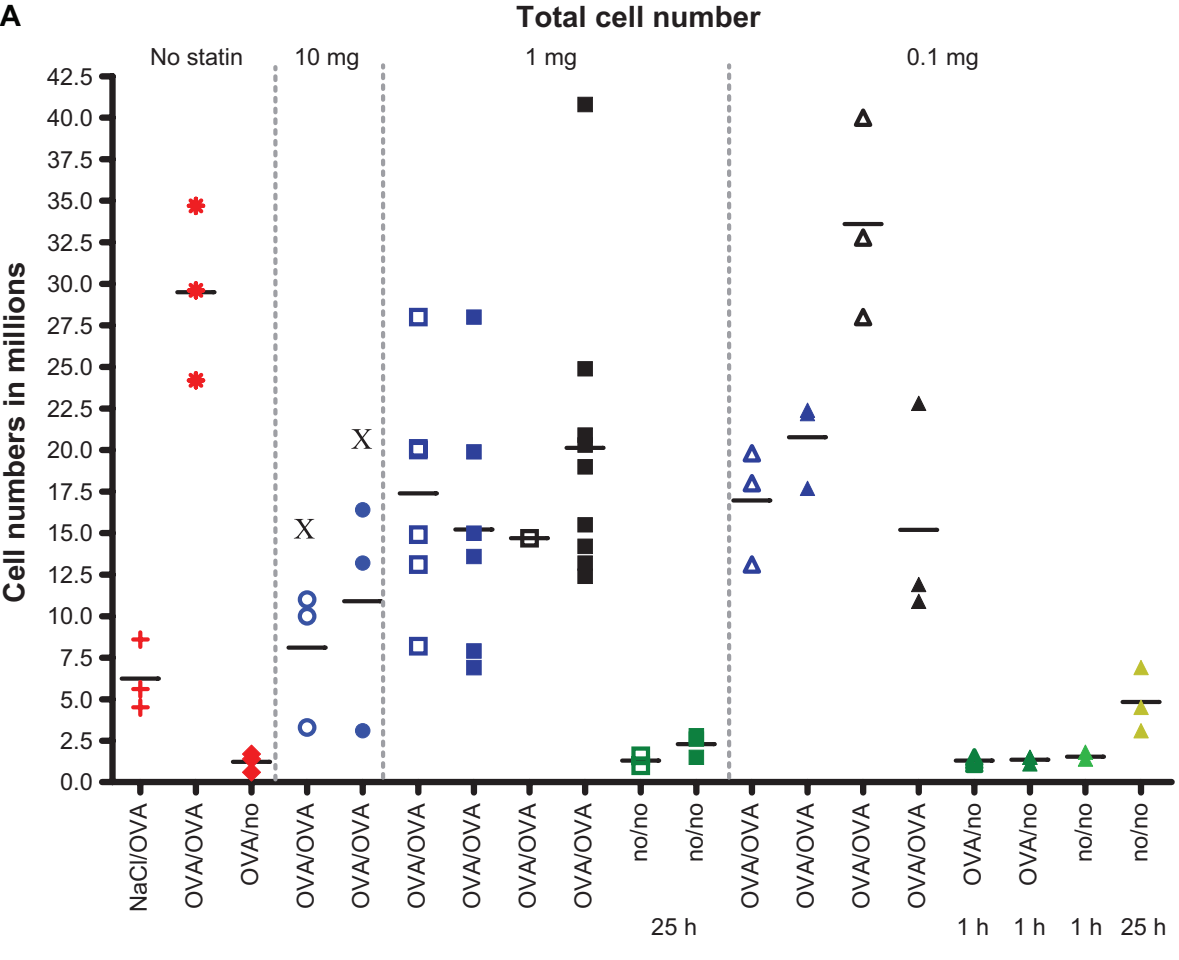

Blue dots $=$ i.p.

Black dots $=$ i.t.

Green dots = control

\section{B Lung tissue}

\section{Total cell number}

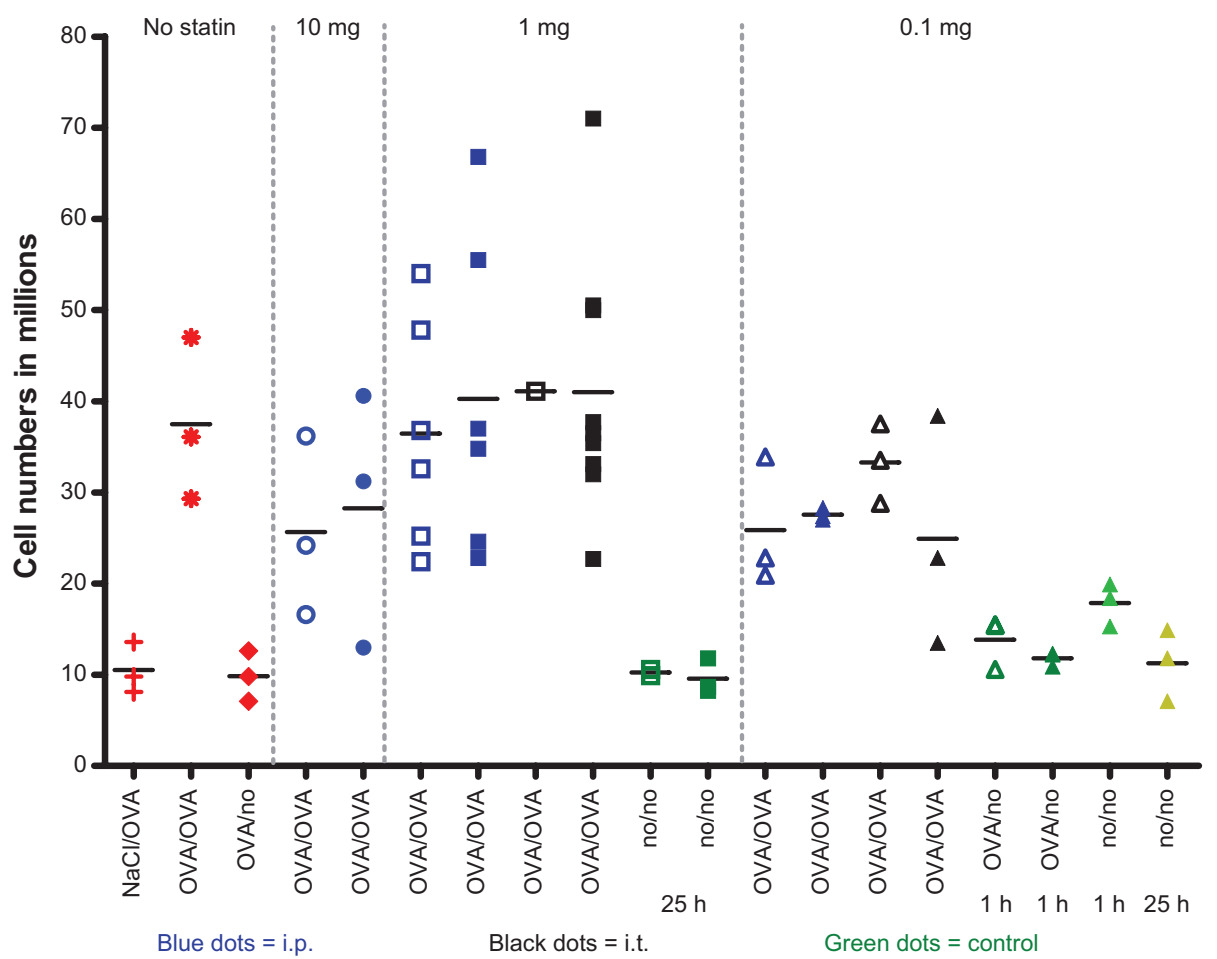

Figure I Single data and mean value of total cell numbers in (A) BAL fluid and (B) in separated lung tissue. There were three animals in each experiment with the following exceptions: statin treatment I mg IP (two experiments each, $\mathrm{n}=6$ ) and statin treatment I mg IT (one experiment, $\mathrm{n}=\mathrm{I}$ and one experiment, $\mathrm{n}=9$ ). The reduction in total cell numbers in BAL fluid after simvastatin $10 \mathrm{mg}$ treatment was significant compared with the control group $(P<0.05)$. No differences were found between cell numbers isolated from lung tissue. Abbreviations: BAL, bronchioalveolar lavage; IP, intraperitoneal; IT, intratracheal. 
A BAL

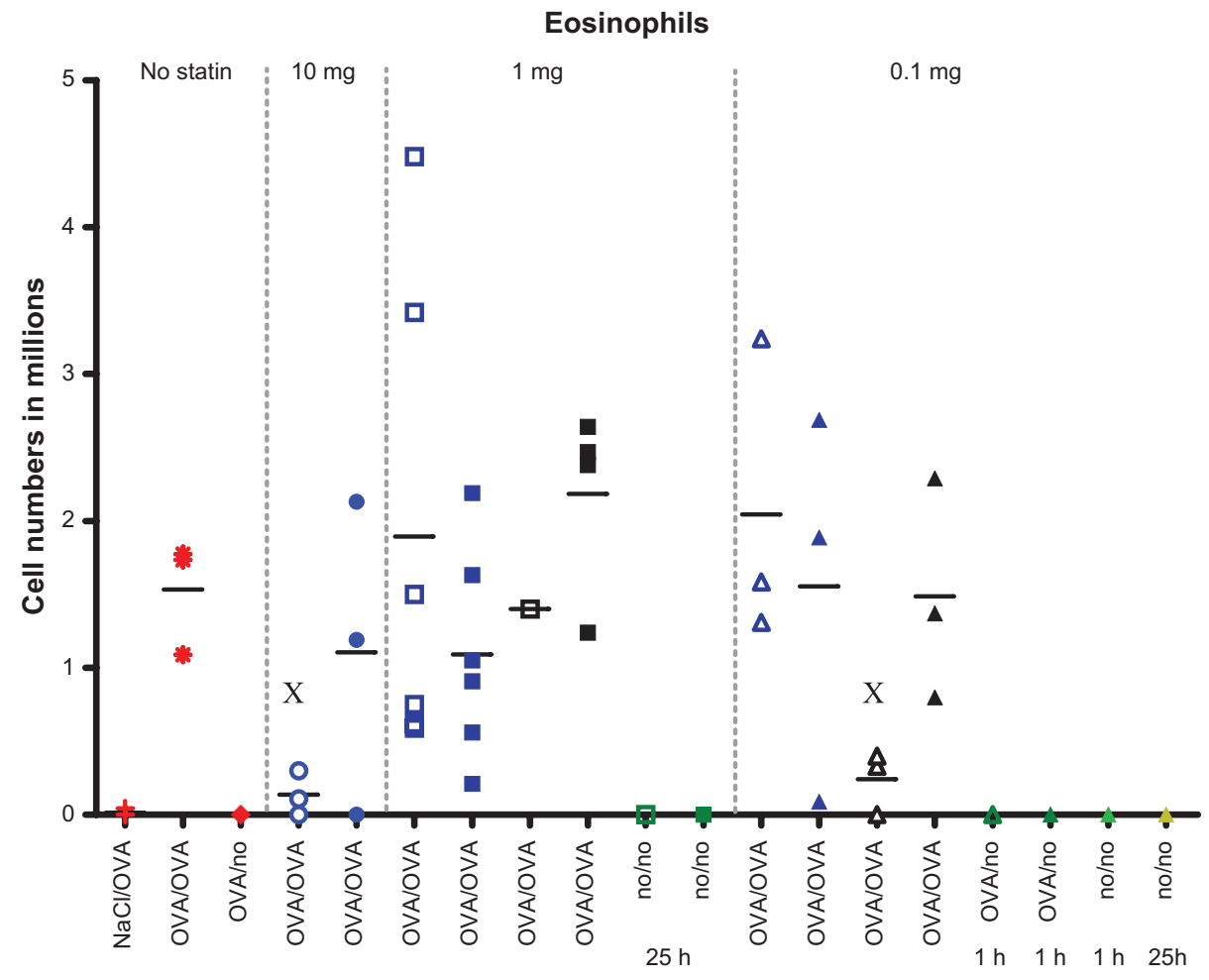

Blue dots $=$ i.p.

Black dots $=$ i.t.

Green dots $=$ control

B BAL

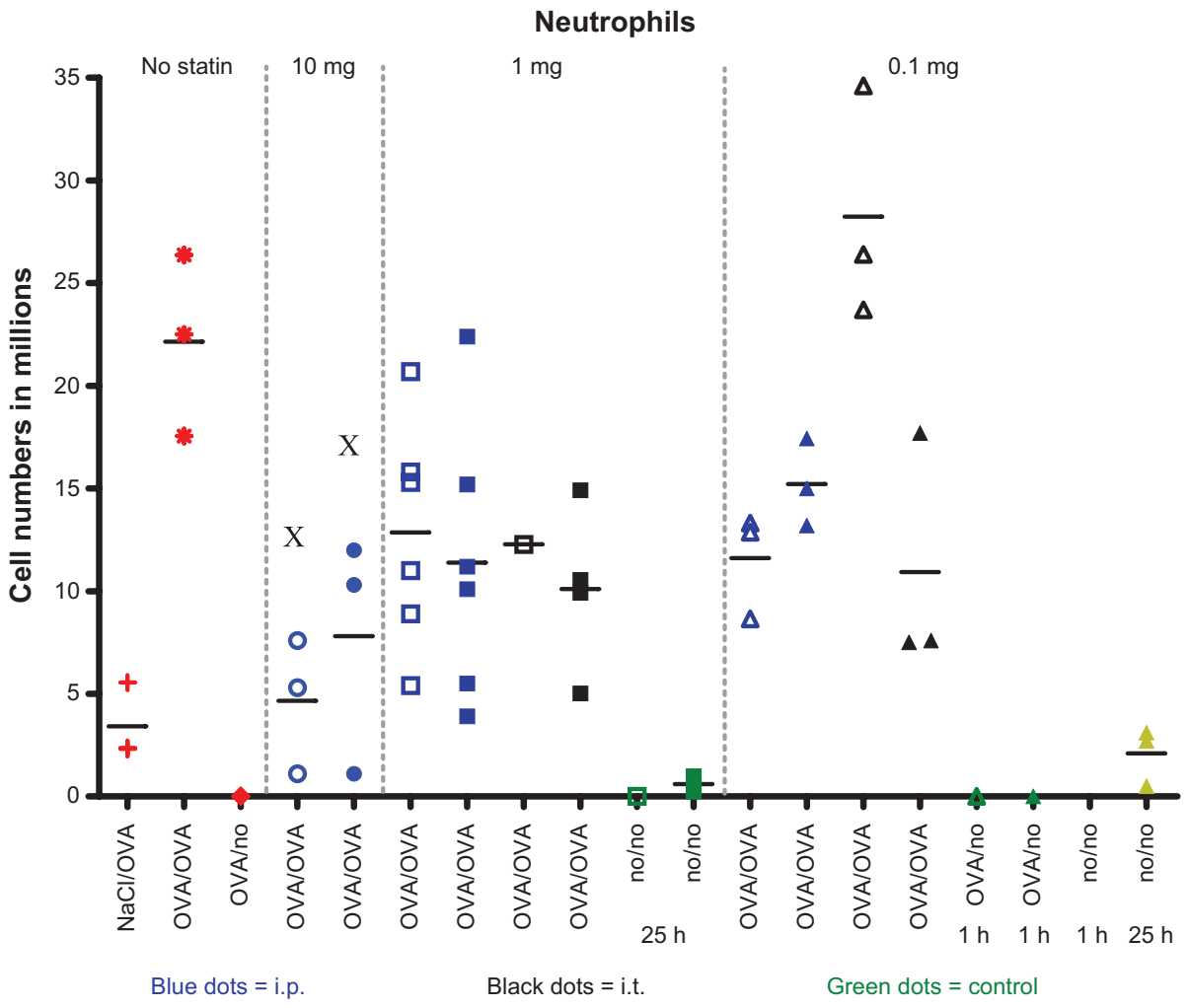

Figure 2 Single data and mean values of (A) eosinophils and (B) neutrophils in BAL fluid. A significant reduction in eosinophil numbers in BAL fluid was found compared with the control groups in the first experiment after simvastatin $10 \mathrm{mg} I \mathrm{P}$ and in the first experiment after simvastatin $0.1 \mathrm{mg} I \mathrm{~T}(P<0.05)$. Neutrophils were reduced significantly after simvastatin $10 \mathrm{mg}$. Abbreviations: BAL, bronchioalveolar lavage; IP, intraperitoneal; IT, intratracheal. 
A BAL

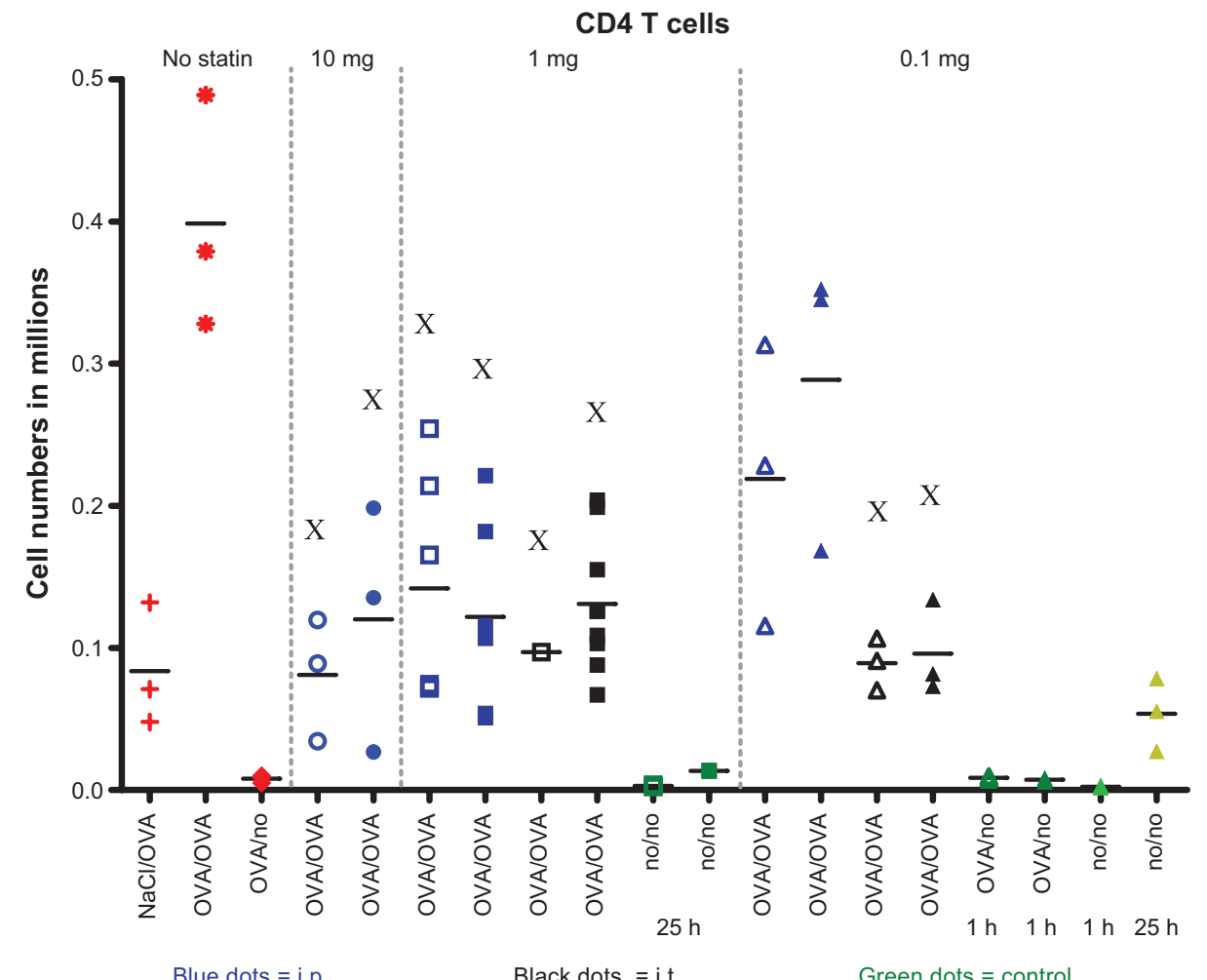

B BAL

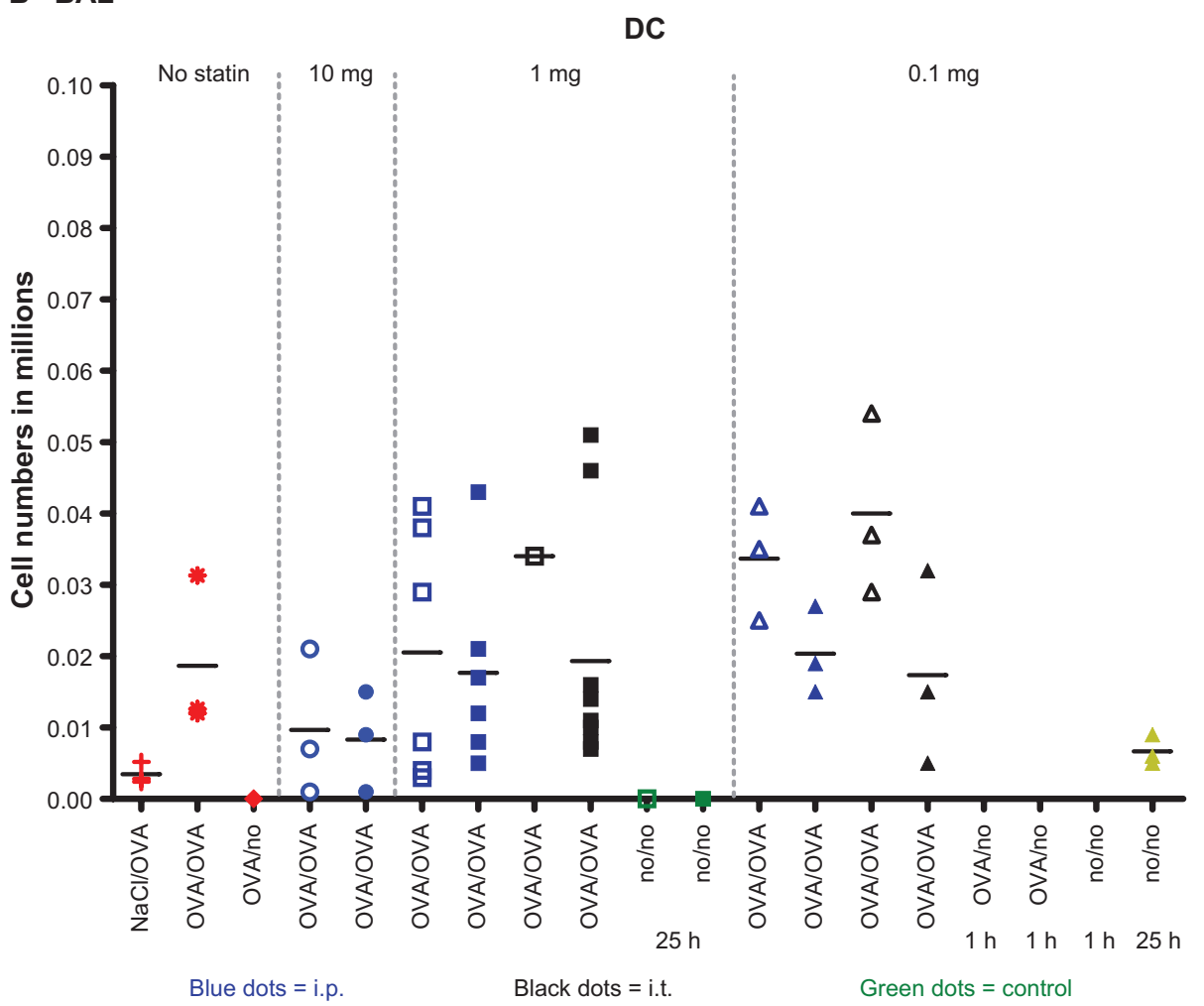

Figure 3 Single data and mean values for $(\mathbf{A})$ CD4 T cells and (B) dendritic cells in BAL fluid. CD4 T cells were significantly reduced in all simvastatin treatment groups except for the two simvastatin $0.1 \mathrm{mg} I \mathrm{P}$ groups $(P<0.05)$. No differences were found between dendritic cell numbers.

Abbreviations: BAL, bronchioalveolar lavage; IP, intraperitoneal; DC, dendritic cells. 
led to a decreased total number of cells in BAL fluid. This was also seen in neutrophils, indicating that neutrophils were the main cell type 24 hours after challenge. Eosinophils are a very important read-out parameter in allergic airway inflammation. A clear-cut effect of simvastatin on the number of eosinophils in BAL fluid was not observed. A reduction in eosinophil numbers was seen in one experiment using IP injection and in another using the IT route. However, in other experiments, no effects on eosinophil numbers were detected. However, $\mathrm{T}$ cells, and especially $\mathrm{CD} 4^{+} \mathrm{T}$ cells, are also very important key players in the pathophysiology of asthma. ${ }^{11} \mathrm{CD} 4{ }^{+} \mathrm{T}$ cells were found to be reduced in the present study, indicating that simvastatin might have a modulatory effect. This might be of interest in the context of T cells producing IL-17.

The discussed mechanisms of simvastatin actions are different. In addition to the aforementioned mechanisms of action for statins, some special actions for simvastatin have been reported. There is a blockade of certain adhesion molecule interactions (lymphocyte function-associated antigen-1, intercellular adhesion molecule-1) and cytokine secretion (interferon-gamma) and also modulation of the so-called mevalonate pathway. ${ }^{3}$ Additionally, distinct inhibitory effects on mitogen-activated protein kinases, small G proteins (eg, Ras, Rho, Rac1, Rac2), and the proinflammatory transcription factor NFKB (but not activator protein-1) by simvastatin were observed in a murine model of asthma. However, the present study focused on endpoints of inflammation and has not analyzed cytokine secretion or transcription factors which might limit the conclusions that could be drawn.

\section{Conclusion}

The complete spectrum of simvastatin effects and their related mechanisms has not been fully elucidated yet. One general problem in experimental asthma models is the time point of intervention. Should the treatment be started prior to sensitization or be started during the sensitization phase? The options are to treat prior to the challenge, prior to each challenge if repeated challenges are performed, or even after the challenge. What might best reflect the normal patient situation? Should the treatment be performed before both, ie, the sensitization and challenge phases? Another difficult issue is the pharmacokinetics of the drug. How long is its duration of action and what is its bioavailability? These questions have to be addressed in all studies dealing with the treatment of experimental asthma. However, the present strategy was to treat once and locally before challenge. Our results support the anti-inflammatory effects of simvastatin, but its role in the treatment of asthma has to be elucidated further.

\section{Acknowledgements}

The authors thank S Weber and K Westermann for their excellent technical assistance, S Fryk for proofreading, and D Stelte and M Peter for assistance with the figures.

\section{Disclosure}

The authors report no conflict of interest in this work.

\section{References}

1. McKay A, Leung BP, McInnes IB, Thomson NC, Liew FY. A novel anti-inflammatory role of simvastatin in a murine model of allergic asthma. J Immunol. 2004;172(5):2903-2908.

2. Hothersall E, McSharry C, Thomson NC. Potential therapeutic role for statins in respiratory disease. Thorax. 2006;61(8):729-734.

3. Kim DY, Ryu SY, Lim JE, Lee YS, Ro JY. Anti-inflammatory mechanism of simvastatin in mouse allergic asthma model. Eur J Pharmacol. 2007;557(1):76-86.

4. Zeki AA, Franzi L, Last J, Kenyon NJ. Simvastatin inhibits airway hyperreactivity: Implications for the mevalonate pathway and beyond. Am J Respir Crit Care Med. 2009;180(8):731-740.

5. Menzies D, Nair A, Meldrum KT, Fleming D, Barnes M, Lipworth BJ. Simvastatin does not exhibit therapeutic anti-inflammatory effects in asthma. J Allergy Clin Immunol. 2007;119(2):328-335.

6. Tschernig T, Neumann D, Pich A, Dorsch M, Pabst R. Experimental bronchial asthma - the strength of the species rat. Curr Drug Targets. 2008;9(6):466-469.

7. Luehrmann A, Deiters U, Skokowa J, et al. In vivo effects of a synthetic 2-kilodalton macrophage-activating lipopeptide of Mycoplasma fermentans after pulmonary application. Infect Immun. 2002;70(7):3785-3792.

8. Chiba Y, Sato S, Misawa M. Lovastatin inhibits antigen-induced airway eosinophilia without affecting the production of inflammatory mediators in mice. Inflamm Res. 2009;58:363-369.

9. Robinson AJ, Kashanin D, O’Dowd F, Fitzgerald K, Williams V, Walsh GM. Fluvastatin and lovastatin inhibit granulocyte macrophagecolony stimulating factor-stimulated human eosinophil adhesion to inter-cellular adhesion molecule-1 under flow conditions. Clin Exp Allergy. 2009;39(12):1866-1874.

10. Hothersall EJ, Chaudhuri R, McSharry C, et al. Effects of atorvastatin added to inhaled corticosteroids on lung function and sputum cell counts in atopic asthma. Thorax. 2008;63(12):1070-1075.

11. Finotto S. T-cell regulation in asthmatic diseases. Chem Immunol Allergy. 2008;94:83-92.

Journal of Asthma and Allergy

\section{Publish your work in this journal}

The Journal of Asthma and Allergy is an international, peer-reviewed open-access journal publishing original research, reports, editorials and commentaries on the following topics: Asthma; Pulmonary physiology; Asthma related clinical health; Clinical immunology and the immunological basis of disease; Pharmacological interventions and

\section{Dovepress}

new therapies. Issues of patient safety and quality of care will also be considered. The manuscript management system is completely online and includes a very quick and fair peer-review system, which is all easy to use. Visit http://www.dovepress.com/testimonials.php to read real quotes from published authors. 